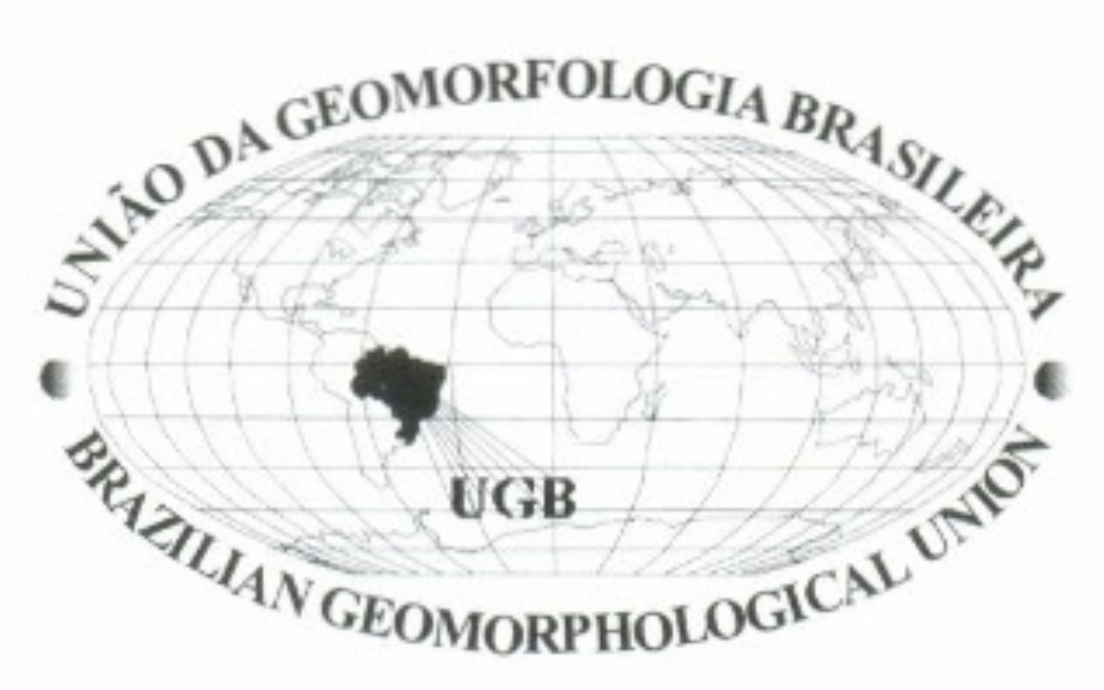

\title{
CORRENTES DE RETORNO E OS RISCOS ASSOCIADOS AO BANHO DE MAR: ESTUDO DE CASO DA PRAIA DO ATALAIA, ITAJAÍ (SC)
}

\author{
Marcos Paulo Berribilli \\ Laboratório de Oceanografia Geológica - CTTMar - UNILAVI \\ Rua Uruguai, 458, Cep: 88302-202, Itajaí - SC \\ berribilli@univali.br \\ Antonio Henrique da Fontoura Klein \\ Laboratório de Oceanografia Geológica - CTTMar - UNILAVI \\ Rua Uruguai, 458, Cep: 88302-202, Itajaí - SC
}

Klein@univali.br

João Thadeu de Menezes

Laboratório de Geoprocessamento e Sensoriamento Remoto CTTMar - UNILAVI Rua Uruguai, 458, Cep: 88302-202, Itajai - SC

thadeu@univali.br

\section{Resumo}

Este trabalho apresenta os perigos naturais (permanentes e não-permanentes) relacionados com o banho de mar, bem como ao uso social da praia do Atalaia, em Itajaí (SC). Para obter essas informações foi necessário mapear a localização das correntes de retorno; classificar o tipo da praia através de levantamentos topográficos e análises granulométricas dos sedimentos; definir os tipos de acidentes e o público usuário. Os dados foram coletados em duas etapas. Na primeira foram coletados dados históricos pesquisados nos arquivos do projeto Gerenciamentoe Segurança nas Praias de 1999 a 2002, e na segunda etapa foram realizados levantamentos em campo nos meses de dezembro de 2002 a fevereiro de 2003 . Constaram de observações in situ das características morfodinâmicas das praias, bem como de informações fornecidas pelos salva-vidas do corpo de bombeiros referentes às ocorrências de acidentes nas praias. Os resultados mostram que a praia do Atalaia apresentou estágios morfodinâmicos dissipativo e intermediário, com arrebentação de onda do tipo deslizante. As correntes de retorno surgiram em sete locais diferentes ao longo da praia e as ocorrências de 200 acidentes (arrastamentos e afogamentos) ocorridos na praia estão relacionados à presença destas correntes. De acordo com os dados coletados a maioria das vítimas que se envolveram nos acidentes são jovens de 11 a 20 anos. O público usuário predominante é de Itajaí, na faixa etária entre 30 a 40 anos. Os perigos não-permanentes da praia do Atalaia são as correntes de retorno e a arrebentação das ondas e os perigos permanentes são os obstáculos como costões rochosos e o molhe.

Palavras-chave: Praia do Atalaia; Correntes de retorno; Acidentes de banho.

\section{Abstract}

This work presents natural hazards (permanent and non-permanent) related to beach bath, as well as to social use of Atalaia Beach in Itajaí city (Santa Catarina state, Southern Brazil). In order to obtain those information it was necessary to map the occurrence of rip currents; classify the type of the beach through topographic survey and grain size analysis of sediments and define the accidents and user public. Data was collected in two phases. Historic data from Beach Safety Program (summers seasons from 1999 to 2002) firstly were collected, while field surveys were carried out from December 2002 to February 2003. Field works are constituted by in situ observation of morphodynamic characteristics, as well as information given by lifeguards regarding accident occurrences in the beach. Atalaia Beach presents dissipative to intermediate morphodynamic stage 
with spilling breaking waves. Rip currents appeared in seven different locations along the beach, and most of 200 accidents are related to presence of those currents, due to its dragging characteristic, and most of the victims were youths between 11 and 20 years. Predominant public users are people between 30 and 40 years from Itajaí city. The non-permanent hazards observed in this beach are the rip currents and the wave breaking, while the permanent ones were obstacles, such as, headlands and the jetty.

Keywords: Atalaia Beach, Rip currents, Accidents of bath.

\section{Introdução}

As praias são bens públicos de uso comum e, portanto, deve ser assegurado acesso livre e franco a elas e ao mar, em qualquer direção ou sentido, ressalvados os trechos considerados de interesse da segurança nacional ou incluídos em áreas protegidas por legislação específica (BRASIL, 1988: LEI FEDERAL $N^{\circ} 7.661 / 88$ ). Desta forma, são ambientes de freqüência poptilar, principalmente no verão, quando os usuários desenvolvem atividades de entretenimento e esportivas.

Short \& Hogan (1994) descreveram os perigos associados ao banho de mar, que foram relacionados às características morfodinâmicas das praias australianas e enfatizaram que o principal motivo de freqüentes afogamentos são as correntes de retorno (Figura 1).

\begin{tabular}{|c|c|c|c|c|c|c|c|c|}
\hline \multirow[t]{2}{*}{ Estado da Praia } & \multicolumn{8}{|c|}{ Altura de Onda (m) } \\
\hline & $<05$ & 05 & 10 & 15 & 2.0 & 2.5 & 30 & $>30$ \\
\hline Dissipativo & 4 & 5 & 6 & 7 & 8 & $9^{*}$ & $10^{*}$ & 10 \\
\hline \begin{tabular}{|l|} 
Banco-Cava \\
Longitudinais
\end{tabular} & 4 & 5 & 6 & $7^{*}$ & $7^{*}$ & $8^{*}$ & 9 & 10 \\
\hline $\begin{array}{l}\text { Banco e Praia } \\
\text { Ritmicos }\end{array}$ & 4 & 5 & 6 & $6^{*}$ & $7^{*}$ & 8 & 9 & 10 \\
\hline $\begin{array}{l}\text { Banco e Correntes de } \\
\text { Retorno Transversos }\end{array}$ & 4 & 4 & 5 & $6^{*}$ & 7 & 8 & 9 & 10 \\
\hline $\begin{array}{l}\text { Crista-Canal ou } \\
\text { Terr. Maré Baixa }\end{array}$ & 3 & $3^{*}$ & $4^{n}$ & 5 & 6 & 7 & 8 & 10 \\
\hline Refletivo & $2^{*}$ & $3^{*}$ & 4 & 5 & 6 & 7 & 8 & 10 \\
\hline \multicolumn{2}{|l|}{ Escala de Segurança } & \multicolumn{7}{|c|}{ Legenda para os Perigos Associados } \\
\hline $\begin{array}{l}\text { Máxima: } \\
\text { Moderada: } \\
\text { Baixa: } \\
\text { Mínima: }\end{array}$ & $\begin{array}{l}1-3 \\
4-6 \\
7-8 \\
9-10\end{array}$ & & & \multicolumn{5}{|c|}{$\begin{array}{l}\text { Profundidade e ou correntes fracas } \\
\text { Arrebentaçăo } \\
\text { Correntes de retorno na zona de surfe } \\
\text { Correntes de retorno e arrebentaçäo } \\
\text { muito alta }\end{array}$} \\
\hline
\end{tabular}

*Nivel de segurança sob condiçồes de ondas modais.

Figura 1 - Índices de periculosidade natural segundo proposta de SHORT \& HOGAN (1994).

As correntes de retorno são formadas pelo refluxo de água que chega à praia empurrada pelas ondas, e variam em tamanho, largura, profundidade e intensidade de acordo com o tipo de praia. Quando as ondas quebram, elas empurram a água acima do nível médio do mar, assim que a energia da água é dissipada e a água que ultrapassou aquele nível médio é empurrado de volta pela força da gravidade em forma de correntes, que podem atingir velocidades de até $3 \mathrm{~m} / \mathrm{s}$.

A praia do Atalaia apresenta uma extensão de $630 \mathrm{~m}$ com uma largura média da faixa de areia de $66 \mathrm{~m}$ e situa-se na foz do rio Itajaí-Açu, no município de Itajaí, SC (Figura 2). De acordo com Hoefel \& Klein (1997) a linha de costa possui orientação norte-sul, entre o promontório Bico de Papagaio ao sul e o guia-corrente do rio Itajaí ao norte. Esta praia é relativamente protegida, tanto da ação de ondas provenientes do sul como do norte e está totalmente exposta às ondas de leste.

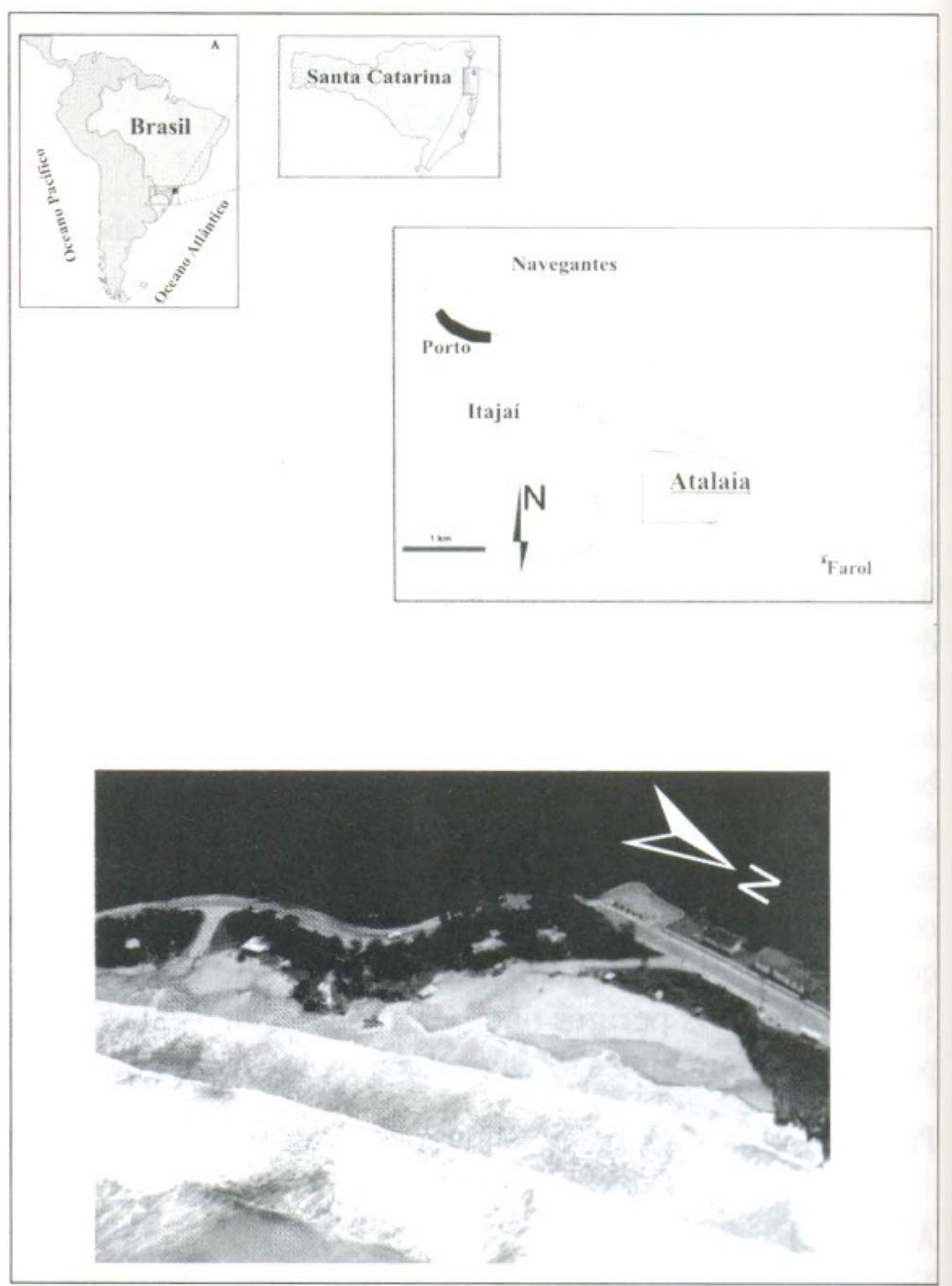

Figura 2 - Localização da área de estudo.

Durante o verão a praia do Atalaia proporciona diversos entretenimentos aos usuários, que geralmente desconhecem os perigos e os riscos que podem resultar em acidentes e até em mortes. 
Os termos perigo e risco têm entrado cada vez mais no vocabulário dos cientistas, embora neste trabalho sejam utilizados com significados diferentes. O perigo restringe-se às características físicas da praia sem envolver o publico usuário e o risco se refere ao fato concreto, quando uma pessoa se expõe ao perigo e pode sofrer algum acidente.

Segundo Carpes Jr. \& Sell (2003) o perigo representa uma energia em estado potencial que, quando ativado, pode ser danosa e causar lesões ou danos materiais. Por outro lado, segundo os mesmos autores, os riscos dependem diretamente do perigo, pois considera a presença de valores humanos e materiais ligados a ele.

As praias podem apresentar dois tipos de perigos, os permanentes como obstáculos, desembocadura de rios e lagos e zona de águas profundas e os não-permanentes, relacionados à arrebentação das ondas, organismos marinhos, raios, correntes e buracos. Os riscos seriam os afogamentos, ferimentos e lesões causados pelos perigos (CTTMar/UNIVALI, 2006).
A escolha da praia do Atalaia, como área de estudo, deve-se aos registros do projeto Segurança nas Praias, desenvolvido pela UNIVALI e o Corpo de Bombeiros de Santa Catarina, quando a praia do Atalaia mostrou o maior número de acidentes por quilômetro de praia do litoral catarinense, porque os banhistas superestimam as suas habilidades de natação e avançam até locais perigosos segundo Hoefel \& Klein (1997). No presente trabalho foram identificadas a natureza e a magnitude dos riscos, associados ao banho de mar na Praia do Atalaia, para subsidiar futuras ações de prevenção.

\section{Material e Métodos}

As etapas de trabalho estão apresentadas na Figura 3. Para observações e coletas de dados hidrodinâmicos foram realizados 68 levantamentos diários de campo na temporada de verão, entre 17 de dezembro de 2002 e 04 de março de 2003.

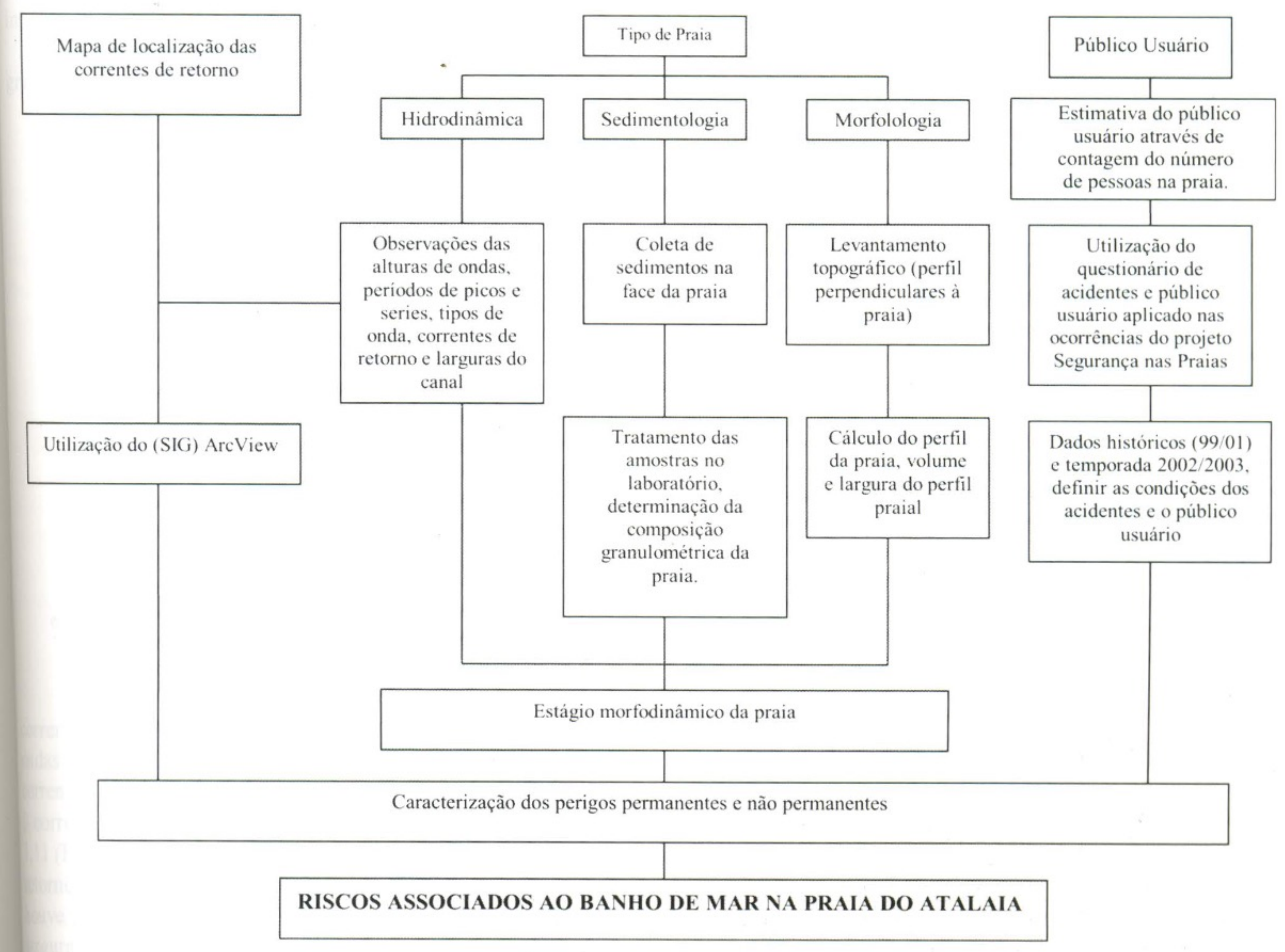

Figura 3 - Fluxograma de etapas que foram seguidas para a execução do projeto. 
Nas saídas de campo foram utilizados mapas da área na escala 1:2.000, para registro dos dados hidrodinâmicos como alturas das ondas nos pontos de arrebentação $(\mathrm{Hb})$, períodos de pico das ondas (Tp) e entre as séries (Ts), tipos de quebras de ondas, localizações das correntes de retorno, estimativas das larguras da zona de surfe, dos canais e números de ocorrência de acidentes (arrastamentos e afogamentos). Os mapas para análise temporal dos dados foram confeccionados por digitalização dos dados no
ArcView GIS 3.2. Os dados também foram tabulados e confeccionados diferentes gráficos.

A morfologia praial foi obtida segundo o método proposto por Borges (1977), através de levantamentos topográficos dos perfis de praia (Figura 4). Os levantamentos consistiram em medições de cotas em quatro perfis perpendiculares à praia, com teodolito eletrônico marca LEIKA 100 e uma régua graduada (mira).

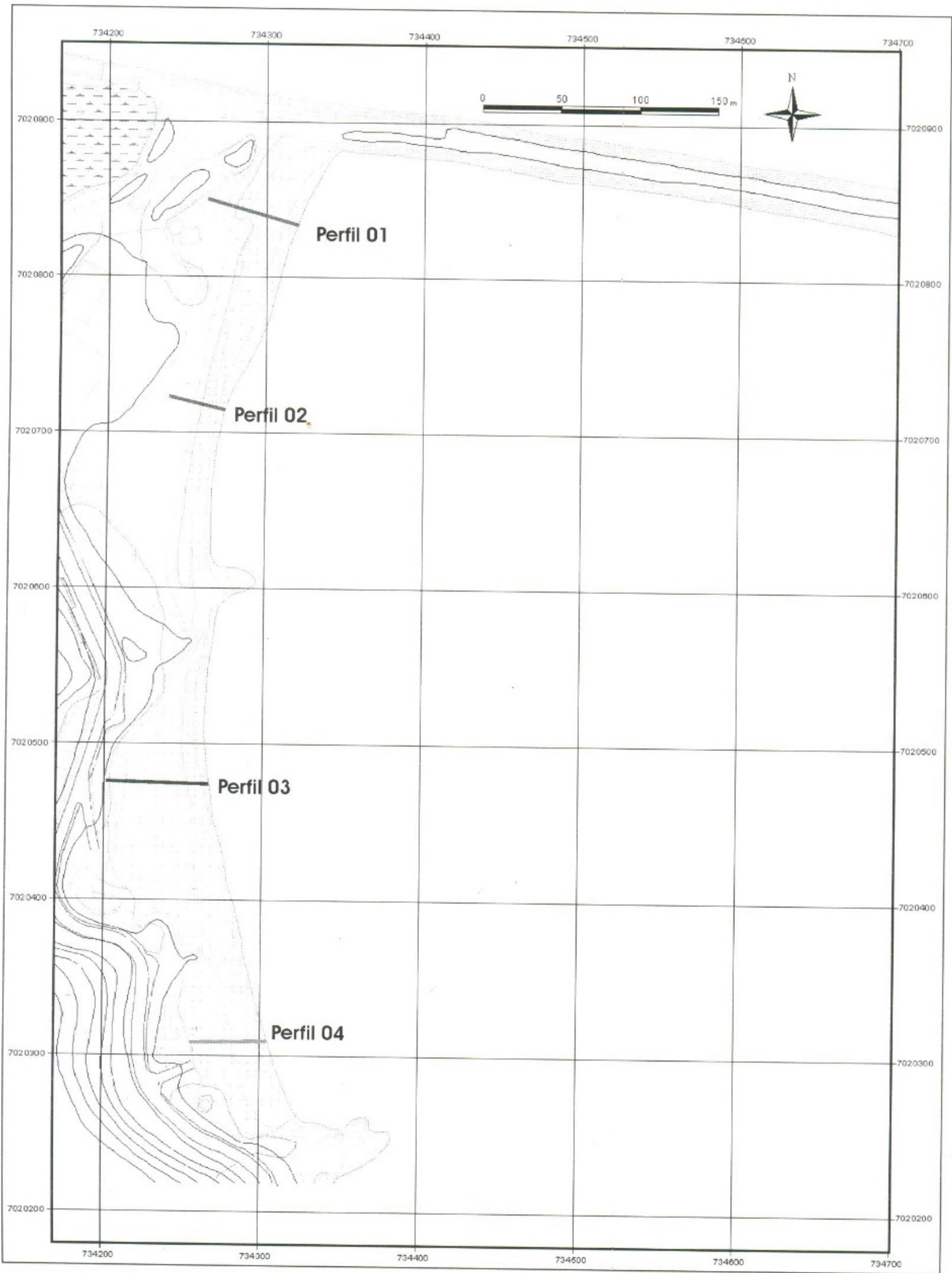

Figura 4 - Locais onde foram levantados os perfis topográficos ao longo da praia do Atalaia. 
As amostragens de sedimentos foram realizadas no ia 23/07/03, em dois pontos ao longo de cada perfil (póspraia e face da praia), totalizando 8 amostras, que foram submetidas a análises granulométricas e posteriormente ao tratamento estatístico por métodos gráficos de Folk \& Ward (1957).

Os estágios morfodinâmicos da praia foram calculados peloparâmetro adimensional ômega (W) proposto por Wright \& Short (1984), que relacionam variáveis quantitativas envolvidas na morfodinâmica de uma praia, caracterizada por intervalos numéricos distintos do parâmetro:

$$
\Omega=\frac{H b}{T \cdot W_{s}}
$$

Aonde : Hb é altura da onda no momento da quebra, T é o período e Ws é a velocidade de sedimentação do grão de sedimento segundo Baba \& Komar (1981).

Valores de ômega superiores a 6 representam praias dissipativas e inferiores a 1 praias reflectivas e as praias intermediárias exibem valores entre 1d" W d" 6.

As posições e números de ocorrências no mapa foram graficadas com auxílio dos salva-vidas na temporada de 2002/2003. As avaliações das condições dos acidentes de banho de mar na praia do Atalaia foram feitas através da interpretação de trezentos questionários do Projeto Gerenciamento e Segurança nas Praias, que foram preenchidos pelos salva-vidas, logo após o atendimento à cada ocorrência entre 1999 a 2002.

A estimativa numérica do público usuário foi realizada através de observações visuais, entre nove e dez horas da manhã, na temporada de 2002/2003, pois, de acordo com os salva-vidas este é o horário quando a praia recebe o maior número de freqüentadores. Os usuários da praia foram observados e contados de elevações naturais para obtenção de um valor estimado de freqüentadores naquele momento.

Os perfis sócio-econômicos dos freqüentadores da Praia do Atalaia foram baseados em 58 entrevistas realizadas entre 1998 a 2003.

\section{Resultados}

Hidrodinâmica

O tipo de arrebentação de ondas predominante na Praia do Atalaia foi o deslizante, com altura média de $0,50 \mathrm{~m}$ e período médio de 9 segundos. A largura média estimada da zona de surfe foi de $90 \mathrm{~m}$ (Tabela 1).

Tabela 1 - Médias e desvio padrão das condições hidrodinâmicas para o número de correntes de retorno da praia do Atalaia na temporada de verão de 2002/2003.

\begin{tabular}{ccccccccc}
\hline Correntes & $\begin{array}{c}\text { Altura de } \\
\text { ondas (m) }\end{array}$ & $\boldsymbol{\sigma}$ & $\begin{array}{c}\text { Período de } \\
\text { pico (seg) }\end{array}$ & $\boldsymbol{\sigma}$ & $\begin{array}{c}\text { Período de série } \\
\text { (seg) }\end{array}$ & $\boldsymbol{\sigma}$ & $\begin{array}{c}\text { Largura da zona } \\
\text { de surfe (m) }\end{array}$ & $\boldsymbol{\sigma}$ \\
\hline Uma & 0,38 & 0,18 & 8,6 & 0,9 & 72,8 & 26,9 & 85 & 19,3 \\
Duas & 0,47 & 0,17 & 9,7 & 1,5 & 88,5 & 42,7 & 99 & 17,5 \\
Três & 0,52 & 0,21 & 9,4 & 1,5 & 95,5 & 55,8 & 86 & 16,1 \\
Quatro & 0,42 & 0,21 & 8,7 & 1,4 & 88,3 & 53,4 & 86 & 14,6 \\
Cinco & 0,75 & 0 & 11,5 & 2,1 & 65 & 21,2 & 106 & 23,3 \\
Seis & 0,75 & 0 & 16 & 0 & 90 & 0 & 105 & 0 \\
\hline
\end{tabular}

$\boldsymbol{\sigma}$ - Desvio Padrão

Em 68 dias de campo, durante apenas três dias, as correntes de retorno estavam ausentes e a altura média das ondas foi inferior $0,40 \mathrm{~m}$. Nos demais dias, ocorreram de 1 a 6 correntes de retorno em 7 locais diferentes, com média de 2 a 3 correntes / dia ao longo da praia, com desvio padrão de 1,11 (Figura 5). A freqüência de ocorrência de correntes de retorno variou conforme o estágio morfodinâmico da praia e houve predominância $(62 \%)$ de correntes de retorno com larguras do canal menores que $15 \mathrm{~m}$, enquanto larguras superiores a $30 \mathrm{~m}$ foram raras (aproximadamente 1\%).

\section{Morfodinâmica}

A praia do Atalaia exibe perfil transversal côncavo e declividade suave na porção superior, que se torna gradativamente convexo próximo à linha de água. A face de praia apresentou declividade média de $3^{\circ} \mathrm{e}$ largura média de $66 \mathrm{~m}$ (Tabela 2).

O diâmetro médio dos sedimentos foi de $0,15 \mathrm{~mm}$ (ou 2,7 fi), classificável como areia fina e bem selecionada, característica de praia dissipativa a intermediária (Tabela 3 ), 


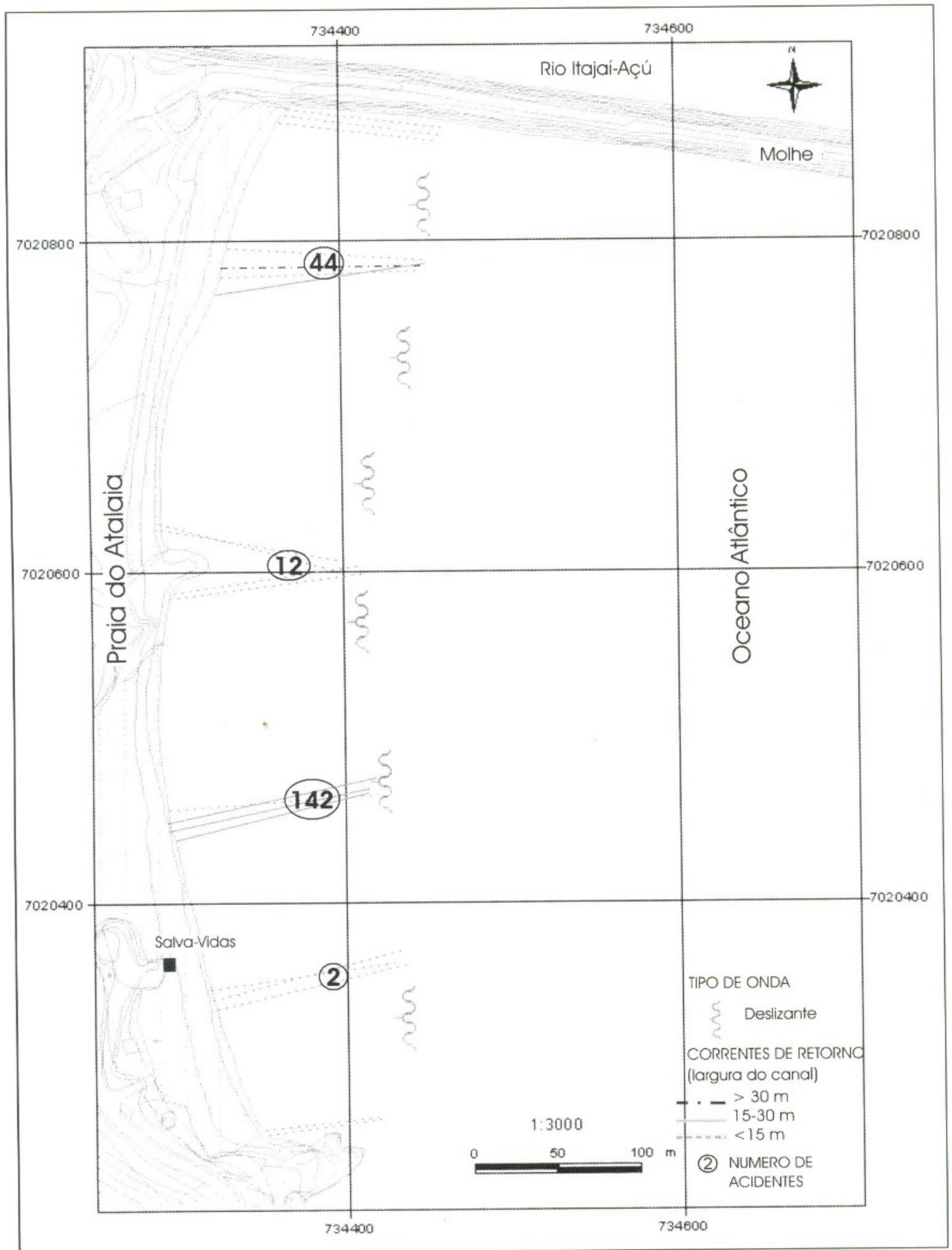

Figura 5 - Localização e número de ocorrências de acidentes na praia do Atalaia durante a temporada de verão de 2002/2003.

Tabela 2 - Valores de largura $(\mathrm{m})$, declividade $\left({ }^{\circ}\right)$ e volume $\left(\mathrm{m}^{3} / \mathrm{m}\right)$ de areia da praia da Atalaia.

\begin{tabular}{cccc}
\hline Perfil & $\begin{array}{c}\text { Largura da faixa de } \\
\text { areia }(\mathbf{m})\end{array}$ & $\begin{array}{c}\text { Declividade da } \\
\text { face da praia }\left(^{(}\right)\end{array}$ & Volume $\left(\mathbf{m}^{3} / \mathbf{m}\right)$ \\
\hline 1 & 80,0 & 2,2 & 79,4 \\
2 & 51,2 & 3,6 & 61,0 \\
3 & 75,0 & 4,1 & 120,5 \\
4 & 57,9 & 2,0 & 35,2 \\
Média & 66,0 & 3,0 & 74,0 \\
Desvio Padrão & 13,7 & 1,1 & 35,9 \\
\hline
\end{tabular}


Correntes de retorno e os riscos associados ao banho de mar: estudo de caso da praia do Atalaia, Itajai (SC)

Tabela 3 - Granulometrias das areias de praia do Atalaia de acordo com FOLK \& WARD (1957).

\begin{tabular}{lcccccc}
\hline \multicolumn{1}{c}{ Posição } & $\begin{array}{c}\text { Diâmetro } \\
\text { médio (fi) }\end{array}$ & $\begin{array}{c}\text { Desvio } \\
\text { padrão }\end{array}$ & $\begin{array}{c}\text { Grau de } \\
\text { assimetria }\end{array}$ & Curtose & $\begin{array}{l}\text { Diâmetro } \\
\text { médio (mm) }\end{array}$ & Grau de seleção \\
\hline Perfil 01 Pós-praia & 2,75 & 0,42 & $-0,006$ & 0,52 & 0,148 & Bem selecionada \\
Perfil 01 Espraiamento & 2,75 & 0,44 & $-0,016$ & 0,47 & 0,148 & Bem selecionada \\
Perfil 02 Pós-praia & 2,62 & 0,44 & $-0,057$ & 0,49 & 0,163 & Bem selecionada \\
Perfil 02 Espraiamento & 2,41 & 0,47 & 0,005 & 0,49 & 0,188 & Bem selecionada \\
Perfil 03 Pós-praia & 2,72 & 0,39 & $-0,029$ & 0,55 & 0,151 & Bem selecionada \\
Perfil 03 Espraiamento & 2,68 & 0,43 & $-0,023$ & 0,49 & 0,156 & Bem selecionada \\
Perfil 04 Pós-praia & 2,80 & 0,39 & 0,026 & 0,54 & 0,143 & Bem selecionada \\
Perfil 04 Espraiamento & 2,78 & 0,44 & $-0,036$ & 0,51 & 0,145 & Bem selecionada \\
\multicolumn{1}{c}{ Média } & 2,69 & 0,43 & $-0,017$ & 0,513 & 0,155 & Bem selecionada \\
\hline
\end{tabular}

$\underline{\text { Tipos de Perigos }}$

Quanto aos perigos associados às praias, a praia do Atalaia apresenta perigos permanentes como a desembocadura fluvial, promontórios rochosos expostos subaereamente e rochas submersas localizadas ao sul da praia, além do molhe no extremo norte da praia. Os perigos não-permanentes estão relacionados à arrebentação das ondas e às correntes de retorno (Figura 6).

\section{Acidentes e Público Usuário}

\section{Temporada 2003-2004}

Foram realizados 200 resgates (salvamentos) na temporada de verão de 2002-2003, mas não ocorreu acidente fatal durante o monitoramento da praia executado pelos salvavidas (Figura 5).

O risco público (correntes de retorno somado a quantidade de pessoas na praia) foi um dos fatores condicionantes mais importantes que desencadearam os acidentes na praia, principalmente nos finais de semana. Isto se deve ao fato de que nos fins de semana e feriados aumenta o número de freqüentadores e, em conseqüência, os de acidentes na praia (Tabela 4).

\section{Dados históricos}

$\mathrm{O}$ principal perigo associado às ocorrências na praia do Atalaia foram as correntes de retorno (73\%), em que $9 \%$ das vítimas estavam sobre influência de álcool e outras drogas. Cerca de $84 \%$ dos acidentes aconteceram no período vespertino entre 15 e 16 horas, quando nos postos de salvavidas a bandeira amarela sinalizava situação de alerta, indicando que o mar estava ruim.

A maioria das vítimas envolvida em ocorrências era do sexo masculino (58\%) e de faixa etária predominante entre 11 a 15 anos (34\%). A maior parte (61\%) é de Itajaí, seguido de outras cidades de Santa Catarina (18\%), de outros estados do Brasil $(20 \%)$ e de outros países ( $1 \%)$.

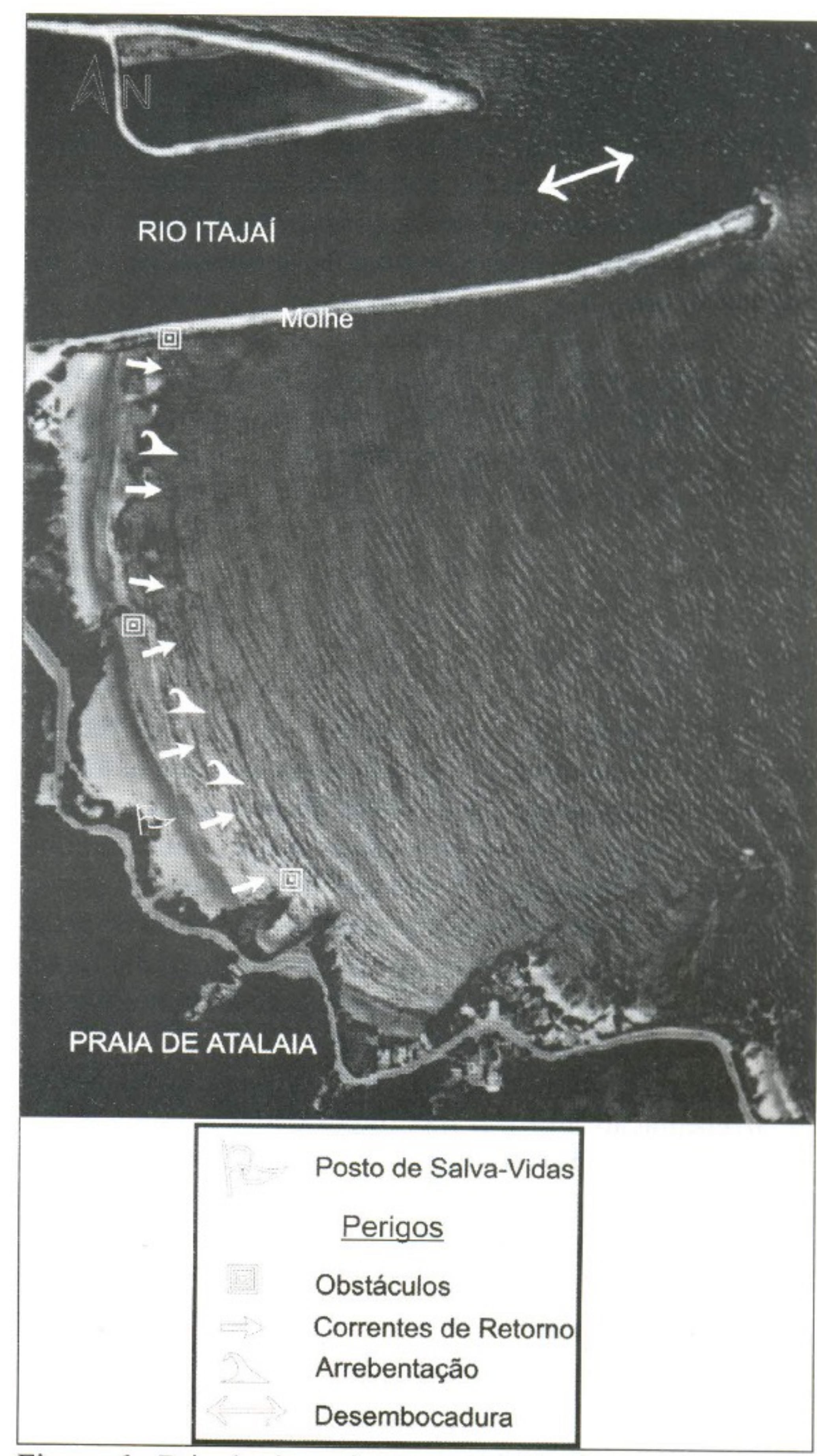

Figura 6 - Principais perigos que a praia do Atalaia oferece aos banhistas. 
Tabela 4 - Freqüências médias de pessoas e de acidentes durante os dias da semana na temporada de verão de 2002/2003.

\begin{tabular}{ccccc}
\hline Dias & N $^{0}$ Pessoas & Desvio padrão & Acidentes & Desvio padrão \\
\hline Segunda & 142 & 130 & 1 & 2 \\
Terça & 142 & 118 & 1 & 3 \\
Quarta & 151 & 136 & 2 & 3 \\
Quinta & 138 & 121 & 1 & 1 \\
Sexta & 138 & 93 & 1 & 2 \\
Sábado & 274 & 208 & 1 & 2 \\
Domingo & 988 & 655 & 13 & 17 \\
Feriado & 498 & 412 & 10 & 16 \\
\hline
\end{tabular}

O público predominante provém de Santa Catarina $(67 \%)$, onde a maioria são moradores de Itajaí, seguido pelos demais estados da Região Sul (19\%), Região Sudeste (9\%) e estrangeiros $(5 \%)$. A faixa etária mais freqüentemente foi entre 15 a 40 anos, o que perfaz quase $50 \%$ dos freqüentadores. Quanto à escolaridade, $18 \%$ dos banhistas entrevistados só tinham o primário, fato que pode dificultar o entendimento das informações sobre os riscos que a praia oferece. Cerca de $23 \%$ dos usuários possuíam uma renda mensal entre 1 e 5 salários mínimos.

Quanto à habilidade à natação, $52 \%$-dos usuários não sabem nadar e cerca de $47 \%$ dos banhistas entram na água até a altura da cintura. A maioria não considera a Praia do Atalaia perigosa, caso sejam respeitadas as bandeiras de sinalização de perigo.

\section{Discussão}

\section{$\underline{\text { Correntes de Retorno }}$}

A freqüência de ocorrência das correntes de retorno variou de 0 a 6 conforme a altura de onda. Quando as alturas das ondas eram inferiores a $0,40 \mathrm{~m}$ foi verificada ausência dessas correntes em toda a extensão da praia. Quanto maiores as alturas das ondas menor é o número de correntes de retorno, embora suas dimensões sejam maiores. Segundo Short \& Brander (1999), a altura de onda é um dos fatores determinantes na diminuição ou aumento do número e nas dimensões das correntes de retorno.

Além da altura de ondas, obstáculos rochosos na zona de arrebentação, influem nas intensidades e larguras dos canais das correntes de retorno.

\section{Nível de Periculosidade}

De acordo com a tabela de níveis de periculosidade para as praias australianas (ver Figura 1) de Short \& Hogan (1994), quando as alturas das ondas são inferiores a $0,50 \mathrm{~m}$, como o caso da praia do Atalaia (média de 0,48 m), e em estado morfodinâmico apresentado por esta praia, tem-se uma escala de segurança moderada, entre 4 e 6.
Entretanto o incremento nas alturas das ondas da arrebentação e também a presença de obstáculos rochosos (promontórios, molhes) fazem com que haja aumento no perigo da praia pela formação de correntes de retorno de forte intensidade (SHORT \& HOGAN, 1994).

\section{Acidentes e Publico Usuário}

Na Figura 7 observa-se que o número de acidentes aumenta proporcionalmente ao número de freqüentadores na praia. Exceção ocorreu no dia 16 de fevereiro de 2004, quando o número de acidentes foi pequeno, apesar do grande número de pessoas, que é explicável pela baixa freqüência de ocorrência de correntes de retorno com intensidades fracas.

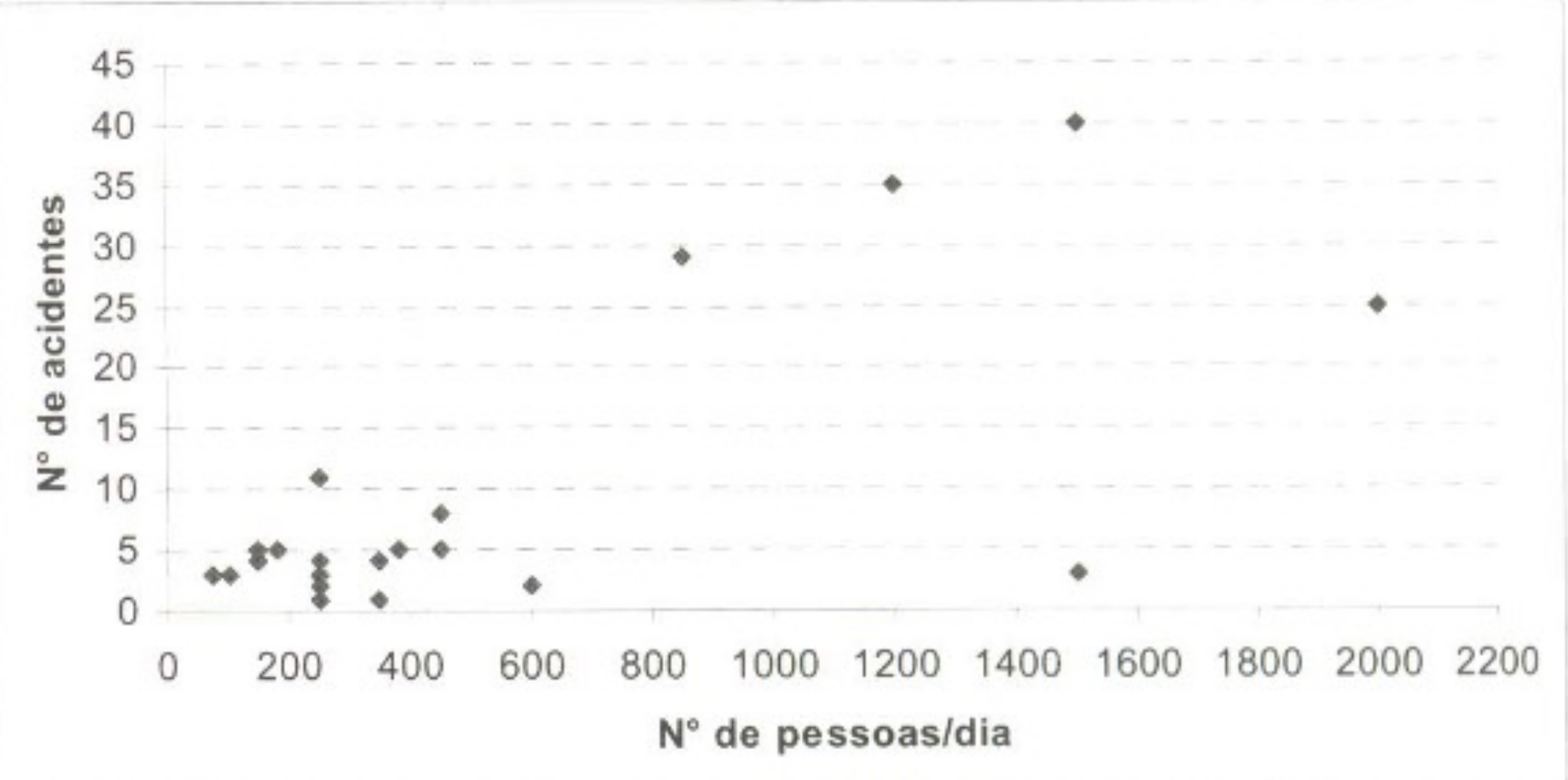

Figura 7 - Números de pessoas e de acidentes na praia do Atalaia durante a temporada de verão de 2002/2003.

No período monitorado, em média 33 ocorrências de acidentes para cada salva-vidas, foram registradas e todos os dia eram designados 6 salva-vidas para o trabalho. 0 local mais crítico situa-se entre dois promontórios rochosos localizados ao sul da praia, onde ocorreram 142 acidentes (ver Figura 5), provocados por correntes de retorno de intensidade forte e canal com largura de 15 a $30 \mathrm{~m} \mathrm{e}$ representaram um alto grau de risco aos banhistas, principalmente porque se encontravam em maior número nesta área. Este local da praia oferece a melhor infra-estrutura e também situa-se mais próximo ao posto de salva-vidas. 
As ocorrências de acidentes de banho possivelmente estão relacionadas à ousadia exagerada dos banhistas, que superestimam as suas habilidades (HOEFEL \& KLEIN, 1997). Em acidentes com pode-se atribuir ao descuido dos pais, quando os filhos menores, adentram ao mar sem o devido cuidado.

\section{Conclusões}

A presença de obstáculos rochosos e o molhe na zona de arrebentação geram correntes de retorno controladas por obstáculos. Além disso, estas surgem em sete locais diferentes ao longo da praia, onde o número de correntes de retorno depende da altura da onda.

Os costões rochosos representam local de perigo permanente aos banhistas, devido aos problemas de quedas e choques. A corrente de retorno foi classificada como de perigo não-permanente mais importante, pois é, responsável por quase $100 \%$ das ocorrências.

Aconteceram 200 ocorrências entre os meses de dezembro, janeiro, fevereiro e março de 2002/2003, em função do elevado número de usuários. Domingos e feriados foram os dias com maior número de freqüentadores e acidentes na praia tendo um total de 134 ocorrências ( 22 ocorrências para cada salva-vidas), ou seja são os dias com maior risco a acidente de banho de mar.

Uma medida para diminuição das ocorrências na praia do Atalaia, seria a alocação de um maior número de salvavidas, nos finais de semana, bem como uma atuação maior na prevenção dos acidentes com campanhas educativas junto aos usuários da praia.

\section{Referências Bibliográficas}

Baba, J., Komar, P.D. (1981) Measurements and analysis of settling velocities of natural quartz sand grains, Jounal of Sedimentary Petrology. v.51, p.631-640.

Borges, A. de C. (1977) Topografia aplicada à engenharia civil. São Paulo: Editora Edgard Blüycher Ltda, vol.1, 187p.

Brasil / (1988). Lei n ${ }^{\circ} 7661$ de 16 de maio de 1988. Institui o Plano Nacional de Gerenciamento Costeiro (PNGC). Brasília, 1988.

Carpes JR., W. P.; Sell, I. (2003) O produto como causador de acidentes. UFSC, ISSN 1676 - 1901,v. 4, n. 2, maio 2003. Revista Produção On line. Disponível em: $<$ http://www.producaoonline.inf.br/v04n02/ artigos/PDF/073_2003.pdf $>$. Acessado em: 10 set. 2006.
CTTMAR/UNIVALI. (2006) Gerenciamento e Segurança nas praias. Disponível em: $<$ http://200.169.63.95/praia/ >. Acessado em: 10 set. 2006.

Folk, R. \& Ward, W. (1957) Brazos river bar: a study in the significance of grain size parameters. Journal of Sedimentary Petrology. v. 27, p. 3-26.

Hoefel, F. G. \& Klein, A. H. da F. (1997) Relatório de Atividades e Resultados do Projeto Segurança nas Praias. Itajaí, $87 \mathrm{p}$.

Short, A. D. \& Brander, R. W. (1999) Regional variations in rip density. Journal of Coastal Research. v.15, p.813-822.

Short, A. D. \& Hogan, C. L. (1994) Rip currents and beach hazards: their impact on public safety and implications for coastal management. Journal of Coastal Research Special Issue: Coastal Hazards. v. 12 , p. $197-20$.

Wright, L.D. \& Short, A. D. (1984) Morphodynamics variability of surf zones and beaches: A synthesis. Marine Geology, v. 56, p. 93-118. 